\title{
Pencegahan primer dan perilaku sehat pada setiap anggota keluarga yang tidak menderita diabetes melitus di dalam keluarga dengan diabetes melitus
}

\author{
Gina Ratna Suminar ${ }^{1 *}$, Citra Windani Mambang Sari², Iwan Shalahuddin ${ }^{3}$
}

\author{
1Mahasiswa, Fakultas Keperawatan, Universitas Padjadjaran, Indonesia. *Email: ginaratsu@gmail.com \\ 2,3 Departemen Keperawatan Komunitas, Fakultas Keperawatan, Universitas Padjadjaran, Indonesia \\ Email: shalahuddin@unpad.ac.id
}

\begin{abstract}
The Primary prevention and healthy lifestyles among non diabetic members of familial type 2 diabetic

Background: Diabetes Mellitus (DM) is one of the diseases that tends to have the increasing rate of incidence. DM can be prevented through preventive and mitigating measures of risk factors that can cause DM, especially in someone who has a history of DM on family members.

Purpose: Describing the primary prevention and healthy lifestyles among non diabetic members of familial type 2 diabetic at Public Health Centre (Puskesmas) the work area of Tarogong, west Java Indonesia.

Methods: A quantitative descriptive with consecutive sampling which was conducted on 138 respondents from the population of 210 family members of patients with DM. Data collection techniques were conducted by using questionnaires to find out and measure DM prevention by healthy lifestyles. The data are grouped into categories of good and poor that were analyzed using descriptive statistics based on the mean value of the questionnaire.

Results: Finding that all respondents $(88.4 \%)$ was in good category in DM prevention by healthy lifestyles. While the behavior of prevention of DM seen from the diet most of the respondents are in good category $(61.6 \%)$, physical activity almost entirely in good category (91.3\%), weight control mostly in category poor (55.1\%), smoking habit almost entirely in category $(86.2 \%)$, and stress management is almost entirely in good category $(87.7 \%)$.

Conclusion: The small percentage of respondents are still lacking of the information about DM, thus becoming poor aware of the importance in doing DM prevention behavior by healthy lifestyles. This happens because most of the respondents have not yet received the necessary information about DM disease. Therefore, it is recommended that the Public Health Centre (Puskesmas) or other local facilities provide information about DM disease not only to the patients but also to their family members.
\end{abstract}

\section{Keywords: The Primary Prevention; Healthy Lifestyles; Type 2 Diabetic}

Pendahuluan: Diabetes Melitus (DM) merupakan salah satu penyakit yang memiliki angka kejadian terus meningkat. DM dapat dicegah melalui tindakan pencegahan dan penanggulangan dari faktor resiko yang dapat menyebabkan DM. Resiko DM lebih besar terjadi pada anggota keluarga yang mempunyai riwayat DM.

Tujuan: Mengidentifikasi gambaran perilaku pencegahan primer pada anggota keluarga dengan DM di wilayah kerja Puskesmas Tarogong.

Metode: Deskriptif kuantitatif dengan menggunakan consecutive sampling yang dilakukan pada 138 responden dari jumlah populasi 210 anggota keluarga penderita DM. Teknik pengumpulan data dilakukan dengan menggunakan kuesioner untuk mengukur perilaku pencegahan DM serta data dikelompokkan ke dalam kategori baik dan buruk yang dianalisis menggunakan statistik deskriptif berdasarkan nilai mean kuesioner.

Hasil: Didapatkan hampir seluruhnya responden $(88.4 \%)$ berada pada kategori baik dalam perilaku pencegahan DM. Sedangkan perilaku pencegahan DM dilihat dari pola makan sebagian besar responden berada pada kategori baik (61.6\%), aktivitas fisik hampir seluruhnya pada kategori baik (91.3\%), pengontrolan berat badan sebagian besar pada kategori buruk $(55.1 \%)$, kebiasaan pengendalikan perilaku merokok hampir seluruhnya pada kategori baik (86.2\%), dan pengelolaan stres hampir seluruhnya pada kategori baik (87.7\%).

Simpulan: Sebagian kecil responden masih buruk dalam melakukan perilaku pencegahan DM. Hal ini terjadi karena sebagian besar responden belum semuanya mendapatkan informasi tentang penyakit DM. Disarankan agar pihak Puskesmas dapat memberikan informasi mengenai penyakit DM tidak hanya pada pasien yang menderita tetapi anggota keluarganya pun perlu diberikan.

Kata kunci: Diabetes Mellitus; Keluarga; Pencegahan; Perilaku 
Pencegahan primer dan perilaku sehat pada setiap anggota keluarga yang tidak menderita diabetes melitus di dalam keluarga dengan diabetes melitus

\section{PENDAHULUAN}

Diabetes Mellitus (DM) merupakan salah satu penyakit yang memiliki angka kejadian terus meningkat. Menurut International Diabetes Federation (IDF) tahun 2013 diperkirakan terdapat 382 juta jiwa di seluruh dunia hidup dengan menderita penyakit DM, sedangkan pada tahun 2035 diperkirakan jumlah tersebut akan meningkat menjadi 592 juta jiwa penderita DM. Dari 382 diperkirakan terdapat 175 juta jiwa yang belum terdiagnosis DM. Di Indonesia penyakit DM menempati urutan kelima di dunia. Dibandingkan dengan data IDF tahun 2013, Indonesia naik dua peringkat yang menempati peringkat ketujuh dengan jumlah 7,6 juta orang penyandang DM di Indonesia (Perkumpulan Endokrinologi Indonesia, 2015).

Di Jawa Barat menurut Riset Kesehatan Dasar (2013) prevalensi DM berdasarkan hasil yang sudah terdiagnosa oleh tenaga kesehatan adalah sebesar $1,3 \%$, dan berdasarkan hasil yang sudah terdiagnosa disertai dengan gejala sebesar $2 \%$. Garut merupakan salah satu kota dengan jumlah penderita DM sebesar $62,04 \%$ dengan 5.522 kasus dan sebanyak 3.426 kasus diabetes melitus terjadi pada perempuan dan 2096 kasus terjadi pada laki-laki (Dinas Kesehatan Kabupaten Garut, 2017). Berdasarkan data dari Dinas Kesehatan Kabupaten Garut (2016), Puskesmas Tarogong menjadi urutan pertama kasus DM dengan jumlah 1.169 berdasarkan data kunjungan ke Puskesmas Tarogong dari berbagai wilayah di luar wilayah kerja Puskesmas Tarogong. Sedangkan data berdasarkan kunjungan dari wilayah kerja Puskesmas Tarogong sebanyak 630 dan jumlah penderita DM yang ada di wilayah kerja Puskesmas Tarogong tercatat 210 orang dalam satu tahun pada tahun 2017.

DM merupakan penyakit sistemis, kronis serta multifaktorial yang ditandai dengan hiperglikemia dan hiperlipidemia (Baradero, Dayrit, \& Siswadi, 2009). Tanda dan gejala DM diantaranya yaitu: sering kencing (poliuri), adanya rasa haus yang berlebihan (polidipsi), merasa sangat lapar (poliphagi), kelelahan yang ekstrim, pandangan menjadi kabur, adanya luka atau memar yang proses penyembuhannya lambat, penurunan berat badan yang cepat, kesemutan serta mati rasa pada tangan atau kaki (American Diabetes Association, 2016). Adapun faktor resiko terjadinya DM yaitu, faktor genetik atau keturunan, tidak menjaga pola makan yang baik, kelebihan berat badan atau obesitas, riwayat menderita diabetes selama kehamilan (diabetes gestasional), buruknya aktivitas fisik atau olahraga, serta kebiasaan merokok (American Diabetes Association, 2016; Irawan, 2010).

DM dapat memberikan dampak terhadap kualitas sumber daya manusia serta peningkatan biaya kesehatan yang cukup besar, maka dari itu sangat diperlukan program pengendalian DM (Trisnawati, \& Setyorogo, 2013). DM dapat dicegah, ditunda kedajadiannya atau dihilangkan dengan cara mengendalikan faktor resikonya (Fransiska, 2016). Prinsip dasar pengendalian DM yaitu dengan modifikasi gaya hidup, yaitu mengubah pola hidup yang tidak sehat menjadi pola hidup yang sehat. Pola hidup yang sehat tersebut meliputi pengaturan pola makanan yang baik, olahraga teratur, menghindari perilaku yang beresiko meliputi berhenti merokok dan membatasi konsumsi alkohol (Toharin, Cahyati, \& Zainafree, 2015).

Hasil penelitian antara usia dengan kejadian DM menunjukan adanya hubungan yang signifikan yaitu kelompok usia $<45$ tahun $72 \%$ lebih rendah dibanding kelompok usia $\geq 45$ untuk beresiko menderita DM Tipe 2 (Trisnawati, \& Setyorogo, 2013). Pada individu yang berusia lebih tua terdapat penurunan aktivitas mitokondria di sel-sel otot sebesar $35 \%$, hal ini berhubungan dengan peningkatan kadar lemak di otot sebesar $30 \%$ dan memicu terjadinya resistensi insulin (Trisnawati, \& Setyorogo, 2013).

Hasil penelitian lain, menunjukkan bahwa ada hubungan yang signifikan antara aktivitas fisik dengan kejadian DM Tipe 2. Orang yang aktivitas fisik sehari-harinya berat memiliki resiko lebih rendah untuk menderita DM Tipe 2 dibandingkan dengan orang yang aktifitas fisik sehari-harinya ringan (Trisnawati, \& Setyorogo, 2013). Aktivitas fisik dapat menyebabkan kadar insulin semakin meningkat sehingga kadar gula dalam darah akan berburuk akibatnya pada orang yang jarang berolahraga, zat makanan yang masuk ke dalam tubuh tidak dibakar tetapi ditimbun dalam tubuh sebagai lemak dan gula sehingga jika insulin tidak mencukupi untuk mengubah glukosa menjadi energi maka akan timbul DM (Beteng, 2014).

Diabetes merupakan penyakit genetik atau keturunan, artinya jika orang tua menderita DM, maka anak-anaknya akan menderita diabetes juga

Gina Ratna Suminar", Mahasiswa, Fakultas Keperawatan, Universitas Padjadjaran, Indonesia. *Email: ginaratsu@gmail.com Citra Windani Mambang Sari ${ }^{2}$, Iwan Shalahuddin ${ }^{3}$ Departemen Keperawatan Komunitas, Fakultas Keperawatan,

Universitas Padjadjaran, Indonesia. Email: shalahuddin@unpad.ac.id 
Pencegahan primer dan perilaku sehat pada setiap anggota keluarga yang tidak menderita diabetes melitus di dalam keluarga dengan diabetes melitus

(Kawalot, Kandou, \& Kolibu, 2017). Terbukti dari hasil penelitian yang menunjukkan adanya hubungan antara riwayat keluarga penderita DM dengan kejadian DM tipe 2 dimana pada orang yang mempunyai riwayat keluarga DM mempunyai resiko 2,97 kali di bandingkan pada orang yang tidak mempunyai riwayat keluarga yang menderita DM (Fatmawati, 2010).

Faktor lain yang mempengaruhi resiko terjadinya DM adalah faktor perilaku atau gaya hidup seseorang tersebut. Perilaku tersebut diantaranya yaitu aktivitas fisik yang buruk dan pola makan yang buruk sehat seperti makan makanan tinggi lemak, manis, buruk mengkonsumsi sayur serta buah-buahan. Faktor tersebut bisa dirubah atau dapat dicegah dengan pengaturan pola makan yang baik dan olahraga secara teratur sehingga dapat menurunkan prevalensi terjadinya DM. Jenis diabetes yang paling banyak diderita sekitar 90-95\% menderita diabetes tipe II yaitu tipe diabetes yang seharusnya bisa dicegah (Nuraini \& Supriatna, 2016).

Perilaku pencegahan merupakan aktivitas yang dilakukan seseorang dengan meyakini bahwa dirinya sehat untuk tujuan mencegah atau mengetahui penyakit pada tahap ketika tidak ada gejala apapun. Pada aktivitas ini tidak sama dengan perilaku yang dilakukan dalam pengobatan penyakit yang sudah jelas diagnosanya melalui gejala yang muncul, hasil pemeriksaan, atau menurut pendapat medis. Maka dari itu keputusan untuk melakukan perilaku pencegahan harus didasarkan pada faktor-faktor lain yang sifatnya tidak terlalu objektif dibandingkan tanda gejala atau hasil diagnosis oleh dokter (Larasati, 2017).

Pencegahan berdasarkan konsep lima tingkatan pencegahan yang terdiri dari pencegahan primer yaitu pencegahan yang dilakukan sebelum tejadinya sakit terdiri terdiri dari promosi kesehatan dan perlindungan khusus. Pencegahan sekunder yaitu pencegahan yang dilakukan pada fase awal berlangsungnya sakit terdiri dari deteksi diagnose dini pengobatan yang cepat. Serta pencegahan tersier yaitu upaya untuk membantu memulihkan kesehatan dan mencegah komplikasi rehabilitasi dan pembatasan cacat.
Berdasarkan hasil penelitian yang menyatakan bahwa hal yang perlu dilakukan kepada orang yang mempunyai riwayat keluarga menderita DM tipe 2 adalah melakukan pencegahan primer yaitu dengan promosi kesehatan. Adapun bentuk promosi kesehatan yang diberikan adalah edukasi kepada pasien, meliputi edukasi tentang gizi, pola makan sehat, dan penyakit DM tipe 2 (Larasati, 2017; Juanita, \& Safitri, 2016).

Berdasarkan hasil penelitian lainya, menyatakan bahwa perilaku keluarga terhadap upaya pencegahan primer penyakit DM di Desa le Masen Kecamatan Ulee Kareng Banda Aceh Tahun 2013 berada pada kategori buruk dengan persentase 53,8\% (Mukrawati, 2014). Selain itu hasil penelitian yang mendukung yaitu menunjukkan adanya perilaku pencegahan DM pada dua kelompok kontrol dan eksperimen mengalami peningkatan dari sebelum diberikan intervensi dan sesudah dilakukan intervensi dengan pemberian edukasi mengenai pencegahan DM (Anggraini, 2016). Penelitian ini bertujuan untuk mengidentifikasi gambaran perilaku pencegahan primer pada anggota keluarga dengan DM di wilayah kerja Puskesmas Tarogong.

\section{METODE PENELITIAN}

Penelitian deskriptif kuantitatif untuk menggambarkan tentang perilaku pencegahan pada anggota keluarga dengan riwayat DM di wilayah kerja Puskesmas Tarogong Garut. Adapun data penderita DM tahun 2017 sebanyak 210 pasien yang tinggal di wilayah kerja Puskesmas Tarogong sehingga jumlah anggota keluarga pasien yang tidak menderita DM sebagai populasinya. Pengambilan sampel menggunakan teknik nonprobability sampling dengan pendekatan consecutive sampling yaitu dan didapatkan 138 responden. Teknik pengumpulan data dilakukan dengan menggunakan kuesioner untuk mengukur perilaku pencegahan DM serta data dikelompokkan ke dalam kategori baik dan buruk yang dianalisis menggunakan statistik deskriptif berdasarkan nilai mean kuesioner.

Gina Ratna Suminar ${ }^{{ }^{*}}$, Mahasiswa, Fakultas Keperawatan, Universitas Padjadjaran, Indonesia. *Email: ginaratsu@gmail.com Citra Windani Mambang Sari ${ }^{2}$, Iwan Shalahuddin ${ }^{3}$ Departemen Keperawatan Komunitas, Fakultas Keperawatan, Universitas Padjadjaran, Indonesia. Email: shalahuddin@unpad.ac.id 
Pencegahan primer dan perilaku sehat pada setiap anggota keluarga yang tidak menderita diabetes melitus di dalam keluarga dengan diabetes melitus

HASIL

Tabel 1. Distribusi Frekuensi Karakteristik Responden $\mathrm{N}=138$

\begin{tabular}{|c|c|c|c|c|}
\hline \multirow[t]{3}{*}{ Karakteristik } & \multicolumn{4}{|c|}{ Perilaku Pencegahan DM } \\
\hline & \multicolumn{2}{|c|}{ Baik } & \multicolumn{2}{|c|}{ Buruk } \\
\hline & $\begin{array}{c}\text { Frekuensi } \\
\text { (f) }\end{array}$ & $\begin{array}{c}\text { Persentase } \\
(\%)\end{array}$ & $\begin{array}{l}\text { Frekuensi } \\
\text { (f) }\end{array}$ & $\begin{array}{c}\text { Persentase } \\
(\%)\end{array}$ \\
\hline \multicolumn{5}{|l|}{ Usia } \\
\hline$<45$ tahun & 108 & 90 & 12 & 10 \\
\hline$\geq 45$ tahun & 14 & 77.8 & 4 & 22.2 \\
\hline \multicolumn{5}{|l|}{ Jenis Kelamin } \\
\hline Laki-laki & 47 & 74.6 & 16 & 25.4 \\
\hline Perempuan & 75 & 100 & 0 & 0 \\
\hline \multicolumn{5}{|c|}{ Pendidikan Terakhir } \\
\hline SD & 11 & 91.7 & 1 & 8.3 \\
\hline SMP/Sederajat & 21 & 87.5 & 3 & 12.5 \\
\hline SMA/Sederajat & 55 & 84.6 & 10 & 15.4 \\
\hline Perguruan Tinggi & 35 & 94.6 & 2 & 5.4 \\
\hline \multicolumn{5}{|l|}{ Pekerjaan } \\
\hline PNS & 6 & 100 & 0 & 0 \\
\hline Petani & 2 & 100 & 0 & 0 \\
\hline Buruh & 9 & 60 & 6 & 40 \\
\hline Mahasiswa & 12 & 85.7 & 2 & 14.3 \\
\hline Wiraswasta & 31 & 79.5 & 8 & 20.5 \\
\hline Pensiunan & 1 & 100 & 0 & 0 \\
\hline Tidak Bekerja & 33 & 100 & 0 & 0 \\
\hline Lainnya & 28 & 100 & 0 & 0 \\
\hline \multicolumn{5}{|c|}{ Hubungan Dengan Penderita } \\
\hline \multicolumn{5}{|c|}{ Diabetes Melitus } \\
\hline Orangtua & 104 & 88.9 & 13 & 11.1 \\
\hline Saudara Kandung & 18 & 85.7 & 3 & 14.3 \\
\hline \multicolumn{5}{|c|}{ Mendapatkan Informasi tentang DM } \\
\hline $\mathrm{Ya}$ & 46 & 93.9 & 3 & 6.1 \\
\hline Tidak & 76 & 85.4 & 13 & 14.6 \\
\hline
\end{tabular}

Berdasarkan tabel 1, responden dengan jenis kelamin perempuan hampir seluruhnya berada pada karegori baik dalam perilaku pencegahan DM. Responden dengan tingkat pendidikan perguruan tinggi hampir seluruhnya sudah melakukan perilaku pencegahan DM pada kategori baik. Sedangkan responden. Serta responden yang belum mendapatkan informasi mengenai DM hampir seluruhnya sudah melakukan perilaku pencegahan DM dengan baik.

Gina Ratna Suminar", Mahasiswa, Fakultas Keperawatan, Universitas Padjadjaran, Indonesia. *Email: ginaratsu@gmail.com Citra Windani Mambang Sari ${ }^{2}$, Iwan Shalahuddin ${ }^{3}$ Departemen Keperawatan Komunitas, Fakultas Keperawatan, Universitas Padjadjaran, Indonesia. Email: shalahuddin@unpad.ac.id 
Pencegahan primer dan perilaku sehat pada setiap anggota keluarga yang tidak menderita diabetes melitus di dalam keluarga dengan diabetes melitus

Tabel 2. Distribusi Frekuensi Responden Berdasarkan Perilaku Pencegahan N=138

\begin{tabular}{lcccc}
\hline Variabel & \multicolumn{2}{c}{ Baik } & \multicolumn{2}{c}{ Buruk } \\
\cline { 2 - 5 } & $\begin{array}{c}\text { Frekuensi } \\
\text { (f) }\end{array}$ & $\begin{array}{c}\text { Persentase } \\
(\%)\end{array}$ & $\begin{array}{c}\text { Frekuensi } \\
\text { (f) }\end{array}$ & $\begin{array}{c}\text { Persentase } \\
(\%)\end{array}$ \\
\hline $\begin{array}{l}\text { Perilaku Pencegahan Pada } \\
\text { dengan DM }\end{array}$ & 122 & 88.4 & 16 & 11.6 \\
\hline
\end{tabular}

Berdasarkan tabel 2 diketahui bahwa perilaku pencegahan pada anggota keluarga dengan diabetes melitus hampir seluruhnya berada pada kategori baik yaitu sebesar $88.4 \%$ (122 orang) dan sebagian kecil pada kategori buruk sebesar $11.6 \%$ (16 orang).

Tabel 3 Distribusi Frekuensi Responden Berdasarkan Sub Variabel N=138

\begin{tabular}{lcccc}
\hline Sub Variabel & \multicolumn{2}{c}{ Baik } & \multicolumn{2}{c}{ Buruk } \\
\cline { 2 - 5 } & $\begin{array}{c}\text { Frekuensi } \\
(\mathbf{f})\end{array}$ & $\begin{array}{c}\text { Persentase } \\
(\%)\end{array}$ & $\begin{array}{c}\text { Frekuensi } \\
(\mathbf{f})\end{array}$ & $\begin{array}{c}\text { Persentase } \\
(\%)\end{array}$ \\
\hline Pola Makan & 85 & 61.6 & 53 & 38.4 \\
Aktifitas Fisik & 126 & 91.3 & 12 & 8.7 \\
Pengontrolan Berat Badan & 62 & 44.9 & 76 & 55.1 \\
Pengendalikan Kebiasaan Merokok & 119 & 86.2 & 19 & 13.8 \\
Pengelolaan Stres & 121 & 87.7 & 17 & 12.3 \\
\hline
\end{tabular}

Perilaku pencegahan pada anggota keluarga dengan DM dilihat berdasarkan pola makan sebagian besar responden mempunyai kebiasaan pola hampir separuhnya berada pada kategori buruk sebesar 38.4\% (53 orang). Sebagian kecil aktifitas fisik berada pada kategori buruk sebesar $8.7 \%$ (12 orang), pengontrolan berat badan sebagian besar berada pada kategori buruk sebesar $55.1 \%$ (76 orang), kebiasaan merokok sebagian kecil berada pada kategori buruk sebesar $13.8 \%$ (19 orang), dan pengelolaan stres sebagian kecil berada pada kategori buruk sebesar 12.3\% (17 orang).

\section{PEMBAHASAN}

\section{Gambaran Perilaku Pencegahan Pada Domain Pola Makan}

Menurut hasil penelitian, perilaku pencegahan pada berdasarkan pola makan hampir seluruhnya berada pada kategori baik. Hal ini sesuai dengan penelitian sebelumnya bahwa perilaku keluarga pada domain pola makan berada pada kategori baik diatas $50,5 \%$ (47 responden). Hal ini disebabkan karena responden hampir separuhnya sudah mendapatkan informasi mengenai diabetes melitus sehingga dapat mempengaruhi perilaku dalam pola makan responden (Mukrawati, 2014).
Serta dapat dipengaruhi oleh pendidikan responden hampir separuhnya berada pada tingkat SMA/sederajat sehingga pengetahuan dapat mempengaruhi perilaku responden terhadap upaya pencegahan penyakit diabetes melitus.

Pola makan merupakan suatu cara yang di tempuh seseorang dalam memilih atau menggunakan bahan makanan dalam konsumsi pangan setiap hari yang terdiri dari jadwal makan, jumlah makanan dan jenis makanan sesuai dengan faktor sosial dan budaya dimana mereka tinggal (Safitri, 2016). Konsumsi makanan yang berlebihan dapat menyebabkan jumlah energi yang masuk tidak seimbang di dalam tubuh dengan kebutuhan energi konsumsi makanan tersebut terutama berasal dari jenis makanan yang bersumber karbohidrat dan lemak (Sumangkut, Supit, \& Onibala, 2013).

Hasil penelitian lain yang mengatakan peningkatan glukosa darah pada penderita diabetes melitus lebih tinggi terjadi pada responden yang mempunyai pola makan yang buruk baik. Makanan dapat memegang peranan yang penting dalam peningkatan gula dalam darah. Makanan yang dimakan akan dicerna dalam satu saluran cerna dan kemudian akan diubah menjadi

Gina Ratna Suminar", Mahasiswa, Fakultas Keperawatan, Universitas Padjadjaran, Indonesia. *Email: ginaratsu@gmail.com Citra Windani Mambang Sari ${ }^{2}$, Iwan Shalahuddin ${ }^{3}$ Departemen Keperawatan Komunitas, Fakultas Keperawatan, Universitas Padjadjaran, Indonesia. Email: shalahuddin@unpad.ac.id 
Pencegahan primer dan perilaku sehat pada setiap anggota keluarga yang tidak menderita diabetes melitus di dalam keluarga dengan diabetes melitus

suatu bentuk glukosa (Sumangkut, Supit, \& Onibala, 2013).

\section{Gambaran Perilaku Pencegahan Pada Domain Aktivitas Fisik}

Pada domain aktivitas fisik responden sebagian kecil masih ada pada kategori buruk, hasil ini sama dengan hasil penelitian sebelumnya dilihat dari aktivitas fisik yang berada pada kategori buruk masih tinggi mencapai $58.1 \%$ (54 orang). Hal ini disebabkan karena masih banyaknya keluarga yang belum secara optimal melakukan olahraga rutin walaupun dalam waktu 20-30 menit per hari. Mereka beranggapan bahwa melakukan pekerjaan sehari-hari seperti beres-beres rumah sudah merupakan bagian dari olahraga terbukti dari hasil jawaban kuesioner responden yang sebagian besar menjawab kadang-kadang atau tidak pernah melakukan olahraga tetapi sering melakukan pekerjaan seperti beres-beres di rumah (Fatimah, 2015).

Aktivitas fisik dapat membantu mengontrol gula darah. Glukosa dalam tubuh akan diubah menjadi energi pada saat beraktifitas fisik. Aktivitas fisik dapat menyebabkan kadar insulin semakin meningkat akibatnya kadar gula dalam darah akan menurun. Pada orang yang jarang melakukan olahraga, makanan yang masuk ke dalam tubuh tidak akan dibakar tetapi akan ditimbun dalam tubuh sebagai lemak dan gula. Apabila jumlah kadar insulin tidak mencukupi untuk mengubah glukosa menjadi energy maka akan terjadi peningkatan kadar gula dalam darah dan menyebabkan DM (Astari, 2016).

Hasil penelitian, orang yang tidak melakukan aktivitas fisik dapat menyebabkan meningkatkan resiko terjadinya DM dibandingkan dengan orang yang sering melakukan aktivitas fisik sehari hari seperti jalan ke pasar, mencangkul, mencuci, berkubun, membersihkan rumah lebih rendah terjadi resiko DM (Kurniawaty, \& Yanita, 2016). Penelitian lainya mengatakan bahwa aktivitas olahraga buruk dari 3 kali dalam seminggu selama 30 menit dapat menunjukkan resiko untuk menderita DM lebih tinggi dibandingkan dengan aktivitas olahraga yang rutin (Wicaksono, 2011).

\section{Gambaran Perilaku Pencegahan Pada Domain Pengontrolan Berat Badan}

Pada domain pengontrolan berat badan diketahui sebagian besar responden berada pada kategori buruk, hasil ini sebanding dengan hasil penelitian sebelumnya pengontrolan berat badan berada pada kategori buruk masih tinggi sebesar $57.0 \%$ (53 responden). Hal tersebut berhubungan dengan pengaturan pola makan yang buruk oleh keluarga sehingga dapat menyebabkan resiko terjadinya obesitas, seperti sering mengkonsumsi makanan bersantan dan berlemak tinggi akan menyebabkan terjadinya peningkatan kolesterol (Mukrawati, 2014).

Pengaruh indeks masa tubuh terhadap DM disebabkan oleh buruknya aktivitas fisik yang dibarengi dengan konsumsi karbohidrat, protein, dan lemak yang tinggi merupakan faktor resiko terjadinya obesitas. Hal tersebut dapat menyebabkan terjadinya peningkatan asam lemak. Peningkatan asam lemak ini dapat menurunkan translokasi transporter glukosa ke membrane plasma akibatnya terjadi resistensi insulin dalam jaringan (Trisnawati, \& Setyorogo, 2013). Pada seseorang yang obesitas, makan yang terlalu berlebihan dapat menyebabkan pengaturan kerja insulin menjadi tidak normal karena adanya lemah yang berlebih yang dapat menyebabkan kemampuan sel beta pancreas dalam mengeluarkan insulin akan menurun akibatnya dapat terjadi diabetes melitus (Nuraini \& Supriatna, 2016).

Hasil penelitian sebelumnya didapatkan bahwa hasil perhitungan Odds Ratio menunjukkan seseorang yang mengalami obesitas mempunyai resiko 7,14 kali lebih besar untuk menderita diabetes melitus dibandingan dengan orang yang mempunyai IMT normal. Hal tersebut sesuai dengan hasil penelitian sebelumnya bahwa individu yang mengalami obesitas mempunyai resiko 2,7 kali lebih besar untuk terkena diabetes melitus dibandingkan dengan individu yang tidak mengalami obesitas (Trisnawati, \& Setyorogo, 2013; Wicaksono, 2011)

\section{Gambaran Perilaku Pencegahan Pada Domain Kebiasaan Merokok}

Pada domain kebiasaan merokok hampir seluruhnya responden mempunyai kebiasaan tidak merokok sehingga masuk kategori baik. Hal ini

Gina Ratna Suminar ${ }^{{ }^{*}}$, Mahasiswa, Fakultas Keperawatan, Universitas Padjadjaran, Indonesia. *Email: ginaratsu@gmail.com Citra Windani Mambang Sari ${ }^{2}$, Iwan Shalahuddin ${ }^{3}$ Departemen Keperawatan Komunitas, Fakultas Keperawatan, Universitas Padjadjaran, Indonesia. Email: shalahuddin@unpad.ac.id 
Pencegahan primer dan perilaku sehat pada setiap anggota keluarga yang tidak menderita diabetes melitus di dalam keluarga dengan diabetes melitus

berbanding terbalik dengan hasil penelitian sebelumnya yang menyatakan sebesar 76,0\% (31 orang) mempunyai kebiasaan merokok atau terpapar asap rokok (Trisnawati, \& Setyorogo, 2013; Anggraini, 2016 ). Perbedaan tersebut dapat disimpulkan bahwa pada penelitian ini sebagian besar responden berjenis kelamin perempuan dari hasil jawaban kuesioner responden hampir seluruhnya menjawab tidak pernah melakukan kebiasaan merokok.

Perokok aktif mempunyai resiko $76 \%$ lebih besar untuk terserang penyakit diabetes melitus dibanding dengan yang tidak terpajan atau tidak merokok (Irawan, 2010). Menurut peneliti seringnya terpapar asap rokok akan menyebabkan meningkatnya kadar gula dalam darah yang disebabkan oleh nikotin yang merangngsang kelenjar adrenal yang berlebihan. Hasil penellitian masih ada responden yang berada pada kategori buruk dalam kebiasan merokok dapat disebabkan karena buruk pengetahuan mengenai bahaya merokok terhadap kejadian penyakit diabetes melitus.

Merokok merupakan salah satu faktor penyebab terjadinya penyakit diabetes melitus. Asap rokok dapat menyebabkan terjadinya peningkatan kadar gula dalam darah akibat adanya pengaruh nikotin yang merangsang kelenjar adrenal (Trisnawati, \& Setyorogo, 2013). Hasil penelitian lain mengatakan bahwa hasil analisis tabulasi silang di dapatkan nilai odds ratio (OR) sebesar 2.9 dan nilai $p=0.0008$. hal tersebut menunjukan bahwa orang yang memiliki kebiasaan merokok mempunyai resiko 3 kali untuk terjadi DM dibandingkan dengan orang yang tidak memiliki kebiasaan merokok (Yanita, \& Kurniawaty, 2016).

\section{Gambaran Perilaku Pencegahan Pada Domain Pengelolaan Stres}

Pada domain pengelolaan stres, responden hampir seluruhnya mempunyai kebiasaan pengelolaan stres pada kategori baik, sebagian besar responden dapat mengatasi stres dengan adaptasi yang baik sebesar $79,2 \%$ dan $46,2 \%$ responden yang tidak dapat beradaptasi dengan stres. Hal ini dilihat dari hasil jawaban kuesioner responden menjawab sering pada pernyataan yang mengenai sikap yang positif yang dilakukan dalam menanggapi masalah yang sedang dihadapinya (Trisnawati, \& Setyorogo, 2013; Pratiwi, Amatiria, \& Yamin, 2014).

Orang yang mengalami stres memiliki resiko 1,67 kali untuk menderita diabetes melitus dibandingkan dengan orang yang tidak mengalami stres. Hasil penelitian lain mengatakan bahwa adanya tekanan pekerjaan yang tinggi serta pada mereka yang tidak dapat menahan pikiran yang dihasilkan oleh stres akan menyebabkan obesitas, sedangkan obesitas dapat meningkatkan resiko terjadinya diabetes melitus (Winne, Widiantini, \& Tafal, 2014).

Menurut hasil penelitian lainnya menyatakan bahwa stres akan menyebabkan produksi hormon pada kortisol yang berlebihan. Hormon ini merupakan jenis hormone yang melawan dari efek kerja insulin sehingga menyebabkan kadar glukosa dalam darah menjadi tinggi. Hormone ini akan menyebabkan sulit tidur, depresi, tekanan darah menurun yang menyebabkan seseorang menjadi lemas dan nafsu makan menjadi berlebih, berat badan menjadi bertambah dan akan menyebabkan salah satu faktor terjadinya diabetes melitus. Pengelolaan stres yang masih buruk dapat memicu seseorang berperilaku tidak baik dalam pola makan, aktifitas fisik, bahkan dapat merubah dari yang tidak merokok menjadi mempunyai kebiasaan merokok (Pratiwi, Amatiria, \& Yamin, 2014).

\section{SIMPULAN}

Berdasarkan hasil penelitian yang dilakukan, dapat ditarik kesimpulan bahwa tingkat perilaku pencegahan pada anggota keluarga dengan diabetes melitus di Wilayah Kerja Puskesmas Tarogong hampir seluruhnya berada pada kategori baik dan sebagian kecil masih ada pada kategori buruk. Sedangkan, perilaku pencegahan pada anggota keluarga dengan DM di dilihat berdasarkan pola makan hampir separuhnya masih ada pada kategori buruk, aktivitas fisik hampir seluruhnya berada pada kategori baik, pengontrolan berat badan sebagian besar berada pada kategori buruk, kebiasaan merokok sebagian kecil masih ada pada kategori buruk, dan pengelolaan stres hampir seluruhnya sudah berada pada kategori baik.

\section{SARAN}

Perlu dilakukan usaha promotif lintas sektoran di wilayah tersebut melibatkan institusi terkait agar

Gina Ratna Suminar ${ }^{*}$, Mahasiswa, Fakultas Keperawatan, Universitas Padjadjaran, Indonesia. *Email: ginaratsu@gmail.com Citra Windani Mambang Sari ${ }^{2}$, Iwan Shalahuddin ${ }^{3}$ Departemen Keperawatan Komunitas, Fakultas Keperawatan, Universitas Padjadjaran, Indonesia. Email: shalahuddin@unpad.ac.id 
Pencegahan primer dan perilaku sehat pada setiap anggota keluarga yang tidak menderita diabetes melitus di dalam keluarga dengan diabetes melitus

lebih memberikan informasi mengenai penyakit diabetes terutama kepada anggota keluarga dari penderita diabetes melitus melalui penyuluhanpenyuluhan, pemasangan foster juga secara langsung dalam program perawatan kesehatan Keluarga.

\section{DAFTAR PUSTAKA}

American Diabetes Association. (2016). Standards of medical care in diabetes-2016: summary of revisions. Diabetes care, 39 (Supplement 1), S4-S5.

https://care.diabetesjournals.org/content/diacar e/39/Supplement_1/S4.full.pdf

Anggraini, U. M. (2016) Pengaruh Program Edukasi Dengan Media Audio Visual Dan Tertulis Terhadap Perilaku Pencegahan Diabetes Melitus Dan Kualitas Hidup Pada Warga Padukuhan Kasihan. http://repository.umy.ac.id/bitstream/handle/123 456789/2775/12.\%20LAMPIRAN.pdf?sequence $=11 \&$ isAllowed=y

Astari, R. (2016). Hubungan antara kepatuhan terapi diet dan kadar gula darah puasa pada penderita diabetes melitus tipe 2 di wilayah kerja puskesmas purnama pontianak. Jurnal Mahasiswa PSPD FK Universitas Tanjungpura, $5(1)$. http://jurnal.untan.ac.id/index.php/ffk/article/vie wFile/20214/16580

Baradero, M., Dayrit, M. W., \& Siswadi, Y. (2009) Seri Asuhan Keperawatan Klien Gangguan Ginjal, Jakarta: Buku Kedokteran EGC, hal. doi: 10.1371/journal.pone. 0122896 .

https://scholar.google.co.id/scholar?hl=id\&as_s $\mathrm{dt}=0 \% 2 \mathrm{C} 5 \& \mathrm{q}=$ Seri+Asuhan+Keperawatan+Klie $\mathrm{n}+$ Gangguan+Ginjal\%2C+Jakarta\%3A+Buku+ Kedokteran+EGC\&btnG=

Betteng, R. (2014). Analisis Faktor Resiko Penyebab Terjadinya Diabetes Melitus Tipe 2 Pada Wanita Usia Produktif Dipuskesmas Wawonasa. Jurnal e-Biomedik,2(2). https://ejournal.unsrat.ac.id/index.php/ebiomedi k/article/view/4554
Dinas Kesehatan Kabupaten Garut. (2017). Profil Kesehatan Kabupaten Garut tahun 2016. Garut: Dinas Kesehatan. https://scholar.google.co.id/scholar?hl=id\&as_s $\mathrm{dt}=0 \% 2 \mathrm{C} 5 \& \mathrm{q}=$ Dinkes + Kabupaten $+\mathrm{Garut} \% 2 \mathrm{C}+$ 2016\&btnG=

Fatimah, R. N. (2015). Diabetes melitus tipe 2. Jurnal Majority, 4(5). http://juke.kedokteran.unila.ac.id/index.php/maj ority/article/viewFile/615/619

Fatmawati, A. (2010). Faktor Risiko Kejadian Diabetes Melitus Tipe 2 Pasien Rawat Jalan (Studi Kasus di Rumah Sakit Umum Daerah Sunan Kalijaga Demak) (Doctoral dissertation, Universitas Negeri Semarang). https://lib.unnes.ac.id/2428/.

Fransiska, M. (2016). Faktor-Faktor Yang Berhubungan Dengan Kejadian Diabetes Mellitus Tipe II Pada Lansia di Wilayah Kerja Puskesmas Mandiangin Kota Bukittinggi Tahun 2015. Jurnal Kesehatan, 7(2). http://ejurnal.stikesprimanusantara.ac.id/index.p hp/JKPN/article/view/274/pdf.

https://etd.unsyiah.ac.id/index.php?author=\%22 Mukrawati\%22\&search=Search

Irawan, D. (2010). Prevalensi dan Faktor Risiko Kejadian Diabetes Melitus Tipe 2 di Daerah Urban Indonesia (Analisa Data Sekunder Riskesdas 2007) (Doctoral dissertation, Thesis Universitas Indonesia). https://scholar.google.co.id/scholar?cluster=121 $62252441900618248 \& h l=i d \& a s \_s d t=2005 \&$ scio $\mathrm{dt}=0,5$

Juanita, J., \& Safitri, C. P. (2016). Hubungan basic conditioning factors dengan kualitas hidup lanjut usia dengan diabetes melitus di RSUD Dr. Zainoel Abidin Banda Aceh. Idea Nursing Journal, $\quad 7(1)$, 48-60.. http://www.jurnal.unsyiah.ac.id//NJ/article/view/ $6468 / 5305$

Kawalot, A. P., Kandou, G. D. \& Kolibu, F. K. (2017) 'Hubungan Antara Aktivitas Fisik Dan Riwayat Keluarga Dengan Kejadian Diabetes Melitus Tipe 2 Pada Pasien Rawat Jalan Di

Gina Ratna Suminar", Mahasiswa, Fakultas Keperawatan, Universitas Padjadjaran, Indonesia. *Email: ginaratsu@gmail.com Citra Windani Mambang Sari ${ }^{2}$, Iwan Shalahuddin ${ }^{3}$ Departemen Keperawatan Komunitas, Fakultas Keperawatan, Universitas Padjadjaran, Indonesia. Email: shalahuddin@unpad.ac.id 
Pencegahan primer dan perilaku sehat pada setiap anggota keluarga yang tidak menderita diabetes melitus di dalam keluarga dengan diabetes melitus

Wilayah Kerja Puskesmas Tenga Kecamatan Tenga', Media Kesehatan, 9(3). Available at: http://www.ejournalhealth.com/index.php/medkes/ article/view/375.

Kurniawaty, E., \& Yanita, B. (2016). Faktor-faktor yang berhubungan dengan kejadian Diabetes Melitus tipe II. Jurnal Majority, 5(2), 27-31 http://juke.kedokteran.unila.ac.id/index.php/majori ty/article/viewFile/1073/912

Larasati, T. A. (2017). Perbaikan Gaya Hidup Sehat pada Pasien dengan Riwayat Keluarga Diabetes Mellitus Tipe 2 di Puskesmas. Jurnal Kedokteran Universitas Lampung, 1(3), 504-412., http://juke.kedokteran.unila.ac.id/index.php/JK/arti cle/viewFile/1711/1667

Mukrawati, M. (2013). Gambaran perilaku keluarga dalam upaya pencegahan penyakit diabetes mellitus di desa le Masen Kecamatan Ulee Kareng Banda Aceh tahun 2013 https://etd.unsyiah.ac.id/index.php?p=show_detail \&id $=8174$

Nuraini, H. Y., \& Supriatna, R. (2016). Hubungan Pola Makan, Aktivitas Fisik dan Riwayat Penyakit Keluarga Terhadap Diabetes Melitus Tipe 2. Jurnal IImu Kesehatan Masyarakat: The Public Health Science Journal, 5(1), 5-14. http://journals.stikim.ac.id/ojs_new/index.php/jikm/ article/download/14/234

Perkumpulan Endokrinologi Indonesia (2015) Konsensus Pengelolaan dan Pencegahan Diabetes Melitus Tipe 2 di Indonesia 2015, Perkeni. doi: 10.3406/arch.1977.1322. https://s3.amazonaws.com/academia.edu.docum ents/36426530/Konsensus_DM_Tipe_2_Indonesi a_2011_soft_launching_1.pdf?response-contentdisposition=inline \%3B\%20filename\%3DKONSEN SUS.pdf\&X-Amz-Algorithm=AWS4-HMACSHA256\&X-Amz Credential=AKIAIWOWYYGZ2Y53UL3A\%2F2019 1209\%2Fus-east-1\%2Fs3\%2Faws4_request\&XAmz-Date=20191209T004652Z\&X-AmzExpires $=3600 \& X-A m z-S i g n e d H e a d e r s=h o s t \& X-$ Amz-

Signature $=a 3465043513292 \mathrm{ac0f7b7ec30a77a4e}$ b2398be6b95835092bef72d87f514785a
Pratiwi, P., Amatiria, G. \& Sumangkut, S., Supit, W., \& Onibala, F. (2013) 'Hubungan pola makan dengan kejadian penyakit diabetes melitus tipe 2 di poli interna blu.rsup.prof.dr.r.d.kandou manado', Jurnal keperawatan, 1(1), pp. 1-6. https://www.neliti.com/publications/111179/hubun gan-pola-makan-dengan-kejadian-penyakitdiabetes-melitus-tipe-2-di-poli-int

Toharin, S. N., Cahyati W. H., \& Zainafree, I. (2015). Hubungan Modifikasi Gaya Hidup Dan Kepatuhan Konsumsi Obat Antidiabetik Dengan Kadar Gula Darah Pada Penderita Diabetes Melitus Tipe 2 Di Rs Qim Batang Tahun 2013. Unnes Journal of Public Health, 4(2). https://journal.unnes.ac.id/sju/index.php/ujph/articl e/view/5193

Trisnawati, S. K. \& Setyorogo, S. (2013) 'Faktor risiko kejadian diabetes melitus tipe II di puskesmas kecamatan cengkareng jakarta barat tahun 2012', Jurnal imiah kesehatan, 5(1), pp. 6-11. doi: 10.1016/j.ajo.2011.08.043.

https://webcache.googleusercontent.com/search? q=cache:Up6wl1Tge2EJ:https://www.academia.e du/37555316/Faktor_Risiko_Kejadian_Diabetes_ Melitus_Tipe_II_Di_Puskesmas_Kecamatan_Cen gkareng_Jakarta_Barat_Tahun_2012+\&cd=2\&hl= id\&ct=clnk\&gl=id

Wicaksono, R. P. (2011) Faktor-Faktor Yang Berhubungan Dengan Kejadian Diabetes Melitus Tipe 2 (Studi Kasus di Poliklinik Penyakit Dalam Rumah Sakit Dr. Kariadi (Doctoral dissertation, Faculty of Medicine). http://eprints.undip.ac.id/37123/1/Radio_P.W.pdf

Winne, Widiantini, \& Tafal, Z. (2014) 'Aktivitas Fisik, Stres, dan Obesitas pada Pegawai Negeri Sipil', Kesmas: National Public Health Journal, pp. 325329. Available at: https://media.neliti.com/media/publications/39782ID-aktivitas-fisik-stres-dan-obesitas-padapegawai-negeri-sipil.pdf.

Yamin, M. (2014) 'Pengaruh Stress Terhadap Kadar Gula Darah Sewaktu Pada Pasien Diabetes Melitus Yang Menjalani Hemodialisa', Jurnal Kesehatan, 5(1), pp. 11-16. http://ejurnal.poltekkestjk.ac.id/index.php/JK/article/viewFile/59/52

Gina Ratna Suminar ${ }^{{ }^{*}}$, Mahasiswa, Fakultas Keperawatan, Universitas Padjadjaran, Indonesia. *Email: ginaratsu@gmail.com Citra Windani Mambang Sari ${ }^{2}$, Iwan Shalahuddin ${ }^{3}$ Departemen Keperawatan Komunitas, Fakultas Keperawatan, Universitas Padjadjaran, Indonesia. Email: shalahuddin@unpad.ac.id 